\section{AGRIEKONOMIKA}

http://journal.trunojoyo.ac.id/agriekonomika

Volume 10, Nomor 1, 2021

https://doi.org/10.21107/agriekonomika.v10i1.10133
Agriekonomika has been accredited as a scientific journal by the Ministry of

Research-Technology and Higher

Education Republic of Indonesia: No.

23/E/KPT/2019

\title{
Adopsi Inovasi Jajar Legowo oleh Petani di Desa Balahu, Kabupaten Gorontalo
}

\author{
Zulham Sirajuddin \\ Universitas Ichsan Gorontalo, Indonesia
}

Received: Maret 2021; Accepted: April 2021; Published: April 2021

\begin{abstract}
ABSTRAK
Penyuluhan pertanianberperan dalam memperkenalkan metode tanam jajar legowo kepada petani padi dan jagung. Meski begitu, metode tanam jajar legowo belum banyak diadopsi oleh petani. Penelitian ini bertujuan untuk; (1) mengetahui sejauh mana tingkat adopsi jajar legowo oleh petani padi dan jagung berdasarkan tahapan keputusan inovasi pengadopsi, (2) mengetahui persepsi petani terhadap atribut inovasi jajar legowo, (3) mengetahui hubungan antara faktor demografi dengan tingkat adopsi jajar legowo, dan (4) mengetahui hubungan antara persepsi terhadap atribut inovasi terhadap tingkat adopsi jajar legowo. Penelitian ini menggunakan pendekatan deskriptif kuantitatif. Wawancara terstruktur dengan menggunakan lensa teori difusi inovasi disebar kepada 122 responden. Hasil penelitian ini menunjukkan bahwa tingkat adopsi jajar legowo oleh petani padi dan jagung masih tergolong rendah. Petani memiliki persepsi yang cukup baik mengenai observabilitas dan kompatibilitasjajar legowo. Luas lahan dan persepsi petani terhadap kompatibilitas, kompleksitas, maupun observabilitas berkorelasi kuat dengan posisi petani pada tahapan keputusan inovasi jajar legowo.
\end{abstract}

Kata Kunci: Adopsi Inovasi, Atribut Inovasi, Jajar Legowo, Penyuluhan Pertanian, Tahapan Keputusan Inovasi.

Adoption of Jajar Legowo Innovation by Farmers in Balahu Village,Gorontalo Regency

\begin{abstract}
Agricultural extension plays a role in introducing jajar legowo planting method to rice and corn farmers. Nevertheless, it has not been widely adopted. This research aims to; (1) determinethe adoption level of jajar legowo by farmers based on the stages of innovation decision, (2) determine the perceptions of farmer towards the jajar legowo innovation attributes, (3) examine the correlation between demographic factors and the adoption level of jajar legowo, and (4) examinethe correlation between perceived attributes on the adoption level of jajar legowo. Structured interviews using the innovation diffusion theory lens were distributed to 122 respondents. The results indicate that adoption level of jajar legowo is still low. Farmers have a fairly good perception of the observability and compatibility of jajar legowo. Land area and farmers' perceptions of compatibility, complexity, and observability have a strong correlation with the position of farmers at the jajar legowo innovation decision stages.
\end{abstract}

Keywords: Adoption of Innovation, Innovation Attributes, Jajar Legowo, Agricultural Extension, Stages of Innovation Decision 


\section{PENDAHULUAN}

Padi dan jagung merupakan salah satu komoditas prioritas di Indonesia. Padi merupakan komoditas utama sebab sebagian besar penduduk Indonesia mengkonsumsi beras yang berasal dari padi, sementara jagung merupakan bahan baku utama industri peternakan yakni sebagai bahan baku pakan ternak. Oleh karena itu, padi dan jagung menjadi komoditas vital, sebab selain cakupan budidayanya yang luas dan tersebar di seluruh Indonesia, juga karena berhubungan dengan hajat hidup orang banyak. Beragam upaya dilakukan kepada petani untuk meningkatkan produktivitas padi dan jagung, salah satunya dengan menawarkan beragam inovasi yang terbukti secara ilmiah dapat meningkatkan produksi. Penyuluhan pertanian berperan sangat kuat dalam memperkenalkan adopsi inovasi pertanian kepada petani (Gunawan dkk., 2019). Melalui beragam penggunaan metode penyuluhan, petani bersamasama dengan penyuluh mempelajari bagaimana cara penggunaan maupun dampak penggunaan inovasi pertanian untuk meningkatkan produktivitas.

Salah satu inovasi yang banyak ditawarkan kepada petani adalah penggunaan metode tanam jajar legowo sebagai alternatif dari metode tanam konvensional. Beberapa penelitian menunjukkan bahwa metode tanam jajar legowo dapat meningkatkan hasil panen dibandingkan metode tanam lain, misalnya metode tegel. Salah satu contohnya adalah eksperimen yang dilakukan oleh Donggulo dkk. (2017), dimana dalam penelitian tersebut terbukti bahwa penggunaan metode tanam jajar legowo dapat meningkatkan jumlah gabah hasil panen. Petani di Kecamatan Cigasong berpendapat bahwa metode tanam jajar legowo dapat meningkatkan hasil panen hingga $15 \%$ dibanding cara tanam tegel (Aisyah \& Dinar, 2016).

Meski begitu, hingga saat ini belum banyak petani yang mengadopsi jajar legowo dan menggunakannya di lahan. Sebuah penelitian yang dilakukan oleh
Farid dkk. (2018), bahwa mayoritas petani di Desa Sukosari, Malang, tidak menggunakan jajar legowo. Hal ini tercermin dari persentase adopsi jajar legowo di desa tersebut yang hanya mencapai $8,66 \%$ dari total luasan lahan. Faktor faktor umur, profitabilitas dan harga menjadi variabel yang mempengaruhi persepsi petani untuk mengadopsi ataupun menolak jajar legowo di desa tersebut. Dalam penelitian lain yang dilakukan oleh Fachrista dan Sarwendah (2014), terlihat bahwa petani di Desa Labu, Bangka, menunjukkan adopsi yang sangat rendah (di bawah 5\%) meski telah mengikuti kegiatan Pengelolaan Tanaman Terpadu (PTT) yang diselenggarakan oleh penyuluh pertanian untuk memperkenalkan serangkaian inovasi termasuk metode tanam jajar legowo.

Kuntariningsih dan Mariyono (2014) berpandangan bahwa studi adopsi inovasi sangat penting dilakukan untuk membantu mengenali faktor yang menghambat adopsi inovasi di pedesaan, sebab diseminasi teknologi dalam pertanian berkontribusi positif pada penurunan kemiskinan di pedesaan. Merangkum beberapa penelitian mengenai adopsi inovasi jajar legowo di Indonesia, Sirajuddin (2019a) berpendapat bahwa terdapat beragam faktor yang menjadi penghambat adopsi inovasi (termasuk jajar legowo) yang ditawarkan oleh penyuluh kepada petani. Faktor-faktor penghambat tersebut dapat dikategorikan ke dalam beberapa atribut inovasi jajar legowo. Atribut inovasi, sebagaimana dijabarkan oleh Rogers (2003), merupakan cara pandang pengadopsi terhadap karakteristik inovasi yang terdiri atas keuntungan relatif, kompatibilitas, kompleksitas, trialabilitas, dan observasibilitas.

Tujuan penelitian ini adalah untuk; (1) mengetahui sejauh mana tingkat adopsi jajar legowo oleh petani padi dan jagung berdasarkan tahapan keputusan inovasi pengadopsi, (2) mengetahui persepsi petani terhadap atribut inovasi jajar legowo, (3) mengetahui hubungan antara faktor demografi dengan tingkat adopsi jajar 
legowo, dan (4) mengetahui hubungan antara persepsi terhadap atribut inovasi terhadap tingkat adopsi jajar legowo.

\section{METODE PENELITIAN}

Penelitian ini menggunakan pendekatan deskriptif kuantitatif. Penelitian kuantitatif yaitu pendekatan penelitian yang bersandar pada positivisme (Ary dkk., 2018). Penelitian ini dilakukan di Desa Balahu, Kecamatan Tibawa, Kabupaten Gorontalo, Provinsi Gorontalo. Pengambilan data lapangan dilakukan pada bulan JanuariFebruari 2021. Populasi penelitian ini adalah seluruh petani padi dan jagung yang ada di Desa Balahu yang berjumlah 433 orang. Data tersebut diperoleh dari Balai Penyuluhan Pertanian (BPP) yang berlokasi di Kecamatan Tibawa.

Sampel diambil dengan cara aksidental (accidental sampling) yang merupakan non probabilitas sampling. Hal ini dilakukan sebab tidak terdapat daftar nama yang mencakup keseluruhan populasi sehingga tidak memungkinkan untuk melakukan sampel acak sederhana akibat ketiadaan sampling frame. Sampel yang diperoleh dalam penelitian ini berjumlah 122 responden. Wawancara langsung melalui tatap muka (face-to-face) digunakan untuk meningkatkan tingkat respon (response rate) dengan tetap menggunakan protokol kesehatan yang ketat yaitu jaga jarak. Form online Google Form digunakan untuk meminimalisir kontak fisik antara enumerator dengan responden.

Wawancara terstruktur digunakan dalam bentuk kuisioner yang disusun dengan menggunakan lensa teori difusi inovasi yang dikembangkan oleh Rogers (2003). Teori tersebut mencakup tahapan keputusan inovasi (innovation decision stages) dan atribut inovasi (attributes of innovation). Tahapan keputusan inovasiterdiri atas lima tingkatan,yakni tahap pengetahuan (knowledge), tahap persuasif (persuasion), tahap keputusan (decision), tahap implementasi (implementation), dan tahap konfirmasi (confirmation).
Tahapan keputusan inovasi ini kemudian dimodifikasi dalam penelitian ini, dengan menambahkan tahapan tanpa pengetahuan (no knowledge) untuk mengakomodir jawaban responden apabila sama sekali tidak pernah mendengar tentang jajar legowo. Tahapan tanpa keputusan berguna untuk meningkatkan tingkat respon dengan cara memberikan pilihan apabila responden tidak mengetahuitentang sebuah inovasi (Sirajuddin, 2019b; Taylor \& Miller, 2016). Hal tersebut berguna untuk mengurangi resiko tidak menjawab (missing data) olehresponden sehingga dapat lebih akurat dalam mengkategorikan posisi responden dalam tahapan keputusan inovasi jajar legowo. Pernyataan-pernyataan pilihan dalam kuisioner mengenai tahapan keputusan responden dapat dilihat pada Tabel 1.

Variabel pengukuran pada persepsi responden terhadap atribut inovasi dalam penelitian ini terdiri atas keuntungan relatif, kompatibilitas, kompleksitas, trialabilitas, dan observabilitas, yang masing-masing dinilai dengan respon terhadap satu pernyataan sehingga data bersifat ordinal, dimana persepsi tersebut diukur dengan menggunakan skala Likert dengan lima tingkatan yaitu Sangat Tidak Setuju (STS), Tidak Setuju (TS), Netral/Biasa Saja (N), Setuju (S), dan Sangat Setuju (SS). Analisis data dilakukan dengan menggunakan statistik deskriptif untuk menjawab tujuan penelitian 1. Untuk tujuan 2 dan 3, korelasi Spearman's Rank digunakan untuk melihat variabel-variabel yang berasosiatif dengan adopsi inovasi jajar legowo. Data yang diperoleh diolah dengan menggunakan program IBM SPSS Statistics versi 23.

\section{HASIL DAN PEMBAHASAN}

Penelitian ini dilakukan di Desa Balahu. Pemilihan lokasi ini sebab di desa inilah terletak Balai Penyuluhan Pertanian (BPP) Kecamatan Tibawa sebagai pusat penyebaran inovasi pertanian, termasuk jajar legowo. Letak Desa Balahu berada di Kecamatan Tibawa, Kabupaten Gorontalo, Provinsi Gorontalo. Desa 
Balahu merupakan hasil pemekaran dari Desa Isimu Selatan. Secara geografis, Desa Balahu berjarak sekitar $17 \mathrm{~km}$ dari Kecamatan Limboto, yang merupakan pusat ekonomi Kabupaten Gorontalo. Luas lahan keseluruhan di Desa Balahu adalah $443 \mathrm{Ha}$ yang sebagian besar merupakan area pertanian untuk komoditas padi dan jagung, hortikultur, serta perkebunan kelapa.

Bagian utara Desa Balahu berbatasan dengan Desa Isimu Utara, dan bagian selatan dengan Kecamatan Bongomeme. Adapun bagian timur desa berbatasan dengan Kecamatan Limboto Barat, dan sebelah barat dengan Desa Isimu Selatan. Saat ini, jumlah penduduk Desa Balahu adalah 2.720 jiwa (BPS, 2020). Desa Balahu merupakan satu dari 16 desa yang terdapat di Kecamatan Tibawa. Gambar 1 menunjukkan lokasi Desa Balahu dan batas-batasnya. Desa Balahu merupakan salah satu desa penghasil padi dan jagung di Kabupaten Gorontalo. Sebagaimana terlihat pada peta, luas Desa Balahu adalah sekitar $4,4 \mathrm{~km}^{2}$.

Desa Balahu merupakan salah satu desa penghasil pangan padi dan jagung

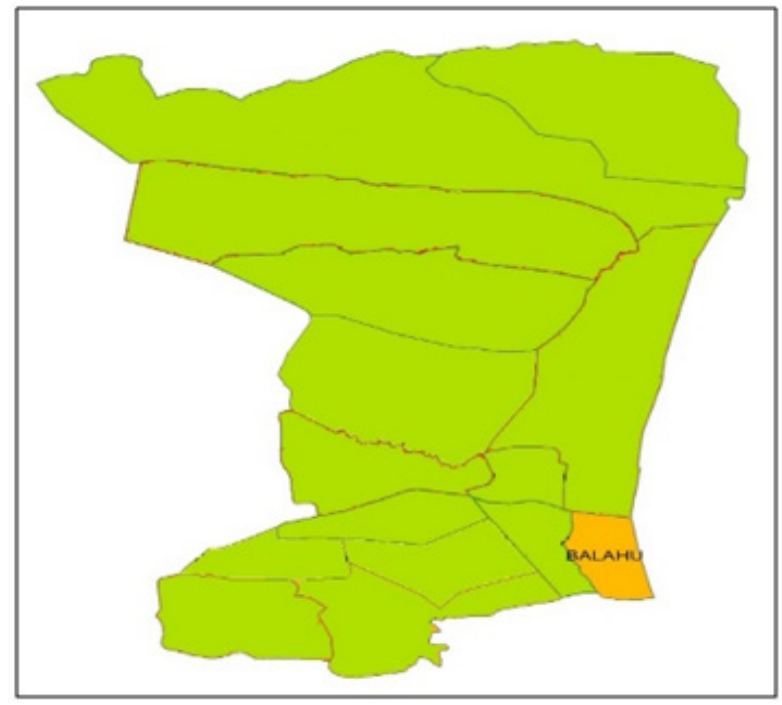

Sumber: Kantor Camat Tibawa, 2021

\section{Gambar 1}

Lokasi Desa Balahu pada Peta Kecamatan Tibawa

Tabel 1

Tahapan Keputusan Inovasi Jajar Legowo

\begin{tabular}{|c|c|}
\hline Tahapan & Pernyataan \\
\hline Tanpa Pengetahuan & Saya belum pernah mendengar tentang jajar legowo \\
\hline Pengetahuan & $\begin{array}{l}\text { Saya pernah mendengar tentang Jajar Legowo, namun saya belum } \\
\text { pernah menggunakannya dan belum berniat mencobanya }\end{array}$ \\
\hline Persuasif & $\begin{array}{l}\text { Saya pernah mencoba Jajar Legowo, namun saya belum menggu- } \\
\text { nakannya sebab saya masih sedang mempelajarinya lebih jauh }\end{array}$ \\
\hline Keputusan & $\begin{array}{l}\text { Saya telah mencoba dan mempelajari Jajar Legowo dan memutus- } \\
\text { kan apakah saya akan menggunakannya atau tidak. }\end{array}$ \\
\hline Implementasi & $\begin{array}{l}\text { Saya telah beberapa kali menggunakan Jajar Legowo, namun saya } \\
\text { masih tetap mempelajari lebih jauh }\end{array}$ \\
\hline Konfirmasi & $\begin{array}{l}\text { Saya telah menggunakan Jajar Legowo cukup lama sehingga saya } \\
\text { benar-benar telah memahami keunggulannya }\end{array}$ \\
\hline
\end{tabular}


Tabel 2

Karakteristik Demografi Responden Tahun 2021

\begin{tabular}{|c|c|c|}
\hline & Jumlah & Persentase \\
\hline Usia & \multicolumn{2}{|c|}{49,58} \\
\hline Di bawah 30 & 6 & $4,9 \%$ \\
\hline $30-39$ & 21 & $17,2 \%$ \\
\hline $40-49$ & 31 & $25,4 \%$ \\
\hline $50-59$ & 34 & $27,9 \%$ \\
\hline 60 keatas & 30 & $24,6 \%$ \\
\hline Luas Lahan & \multicolumn{2}{|c|}{1} \\
\hline Dibawah 0,5 Ha & 18 & $14,8 \%$ \\
\hline 0,5-1 Ha & 85 & $69,7 \%$ \\
\hline $1,1-2 \mathrm{Ha}$ & 13 & $10,7 \%$ \\
\hline $\mathrm{Di}$ atas $2 \mathrm{Ha}$ & 6 & $4,9 \%$ \\
\hline Tanggungan Keluarga & \multicolumn{2}{|c|}{4,34} \\
\hline Dibawah 3 & 16 & $13,1 \%$ \\
\hline $3-5$ & 80 & $65,6 \%$ \\
\hline Diatas 5 & 26 & $21,3 \%$ \\
\hline \multicolumn{3}{|c|}{ Komoditas yang diusahakan } \\
\hline Padi & 90 & $73,8 \%$ \\
\hline Jagung & 24 & $19,7 \%$ \\
\hline Padi dan Jagung & 8 & $6,6 \%$ \\
\hline
\end{tabular}

Sumber: Data Primer Diolah, 2021

di Kabupaten Gorontalo. Lokasinya yang strategis, dimana terdapat jalan poros provinsi yang melintasi bagian utara desa, membuat Desa Balahu memiliki peran yang cukup vital dalam menunjang kesejahteraan dan perekonomian masyarakat Kabupaten Gorontalo. Kebanyakan petani padi menjual hasil panennya ke penggilingan beras yang terdapat di desa, yang kemudian didistribusikan ke pasar-pasar tradisional yang terdapat di sekitar desa ataupun di wilayah lain. Petani jagung umumnya menjual hasil panen berupa pipilan jagung kepada pengumpul yang kemudian membawanya ke industriindustri pengolah pipilan jagung yang cukup banyak terdapat di Kabupaten Gorontalo. Secara umum, jagung pipil tersebut diolah menjadi pakan ternak yang dijual di pasar lokal, pasar regional diluar kabupaten, maupun diekspor ke beberapa negara.

Total responden dalam penelitian ini adalah 122 responden. Sebagaimana ditunjukkan oleh Tabel 2, mayoritas petani responden berusia diatas 50 tahun, dimana hal tersebut mengindikasikan minimnya jumlah petani muda. Kebanyakan responden memiliki luas lahan dibawah 1 $\mathrm{Ha}$. Hal ini disebabkan oleh wilayah Desa Balahu yang tidak terlalu luas dibandingkan desa-desa lainnya sehingga kepadatan penduduknya lebih tinggi. Mayoritas petani responden merupakan petani padi sawah.

\section{Tingkat Adopsi Jajar Legowo}

Tingkatadopsijajar legowo dalam penelitian ini diukur dengan variabel tahapan keputusan inovasi (innovation-decision stages) dengan menambahkan tahapan paling awal yaitu tahap tanpa pengetahuan (no knowledge) sebagaimana terlihat pada Gambar 2.

Gambar 2, menunjukkan bahwa terdapat 44 responden (36\%) mengetahui tentang inovasi jajar legowo namun sama sekali belum pernah mencoba ataupun menggunakannya. Hal tersebut 
menunjukkan bahwa metode tanam jajar legowo cukup populer di kalangan petani, bahkan di kalangan yang belum pernah menggunakannya. Sementara itu, 22 responden $(18 \%)$ sama sekali belum pernah mendengar tentang jajar legowo. Untuk responden yang berada pada tahap keputusan terdiri atas dua, yaitu responden yang telah mencoba dan mempelajari jajar legowo dan memutuskan untuk tidak menggunakannya (3 responden), serta petani yang telah mencoba dan mempelajari jajar legowo dan memutuskan untuk menggunakannya (15 responden). Total pada tahap ini adalah 18 responden. Gambar 2 juga memperlihatkan bahwa diantara total responden, hanya 28 orang $(23 \%)$ yang benar-benar menerapkan jajar legowo dengan cukup yakin, yakni mereka yang berada pada tahap implementasi dan konfirmasi.

Penentuan jumlah pengadopsi (adopter) dalam penelitian ini dilakukan untuk melihat sejauh mana metode tanam jajar legowo telah diadopsi oleh petani di Desa Balahu. Untuk melihat jumlah total pengadopsi tersebut, data pada Gambar 2 dikonversi menjadi dua kategori. Sebagaimana terdapat pada Tabel 3, tahapan keputusan inovasi dibedakan menjadi kategori non-adopter, yaitu petani yang tidak/belum mengadopsi jajar legowo, dan kategori adopter, yaitu petani yang telah mengadopsi jajar legowo. Penentuan kategorisasi dikotomi yakni kategori non-adopter yang melingkupi

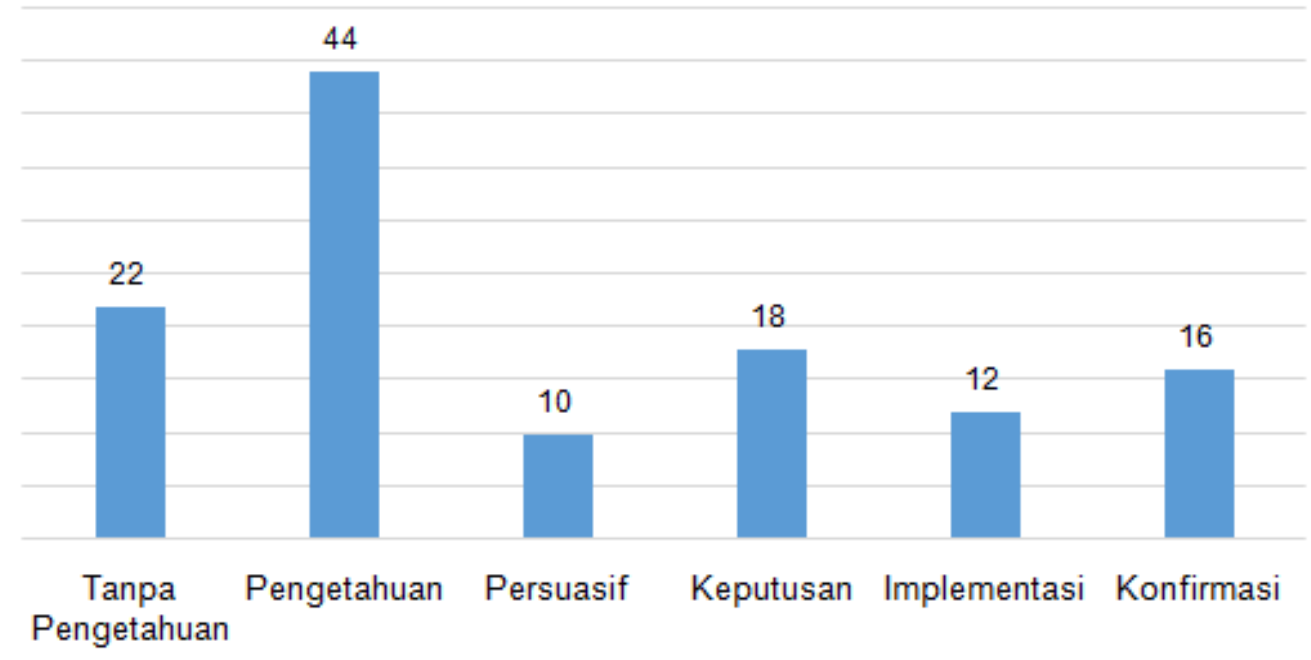

Sumber: Data Primer Diolah, 2021

Gambar 2

Tahapan Keputusan Inovasi Jajar Legowo

Tabel 3

Adopsi Inovasi Jajar Legowo

\begin{tabular}{lcc}
\hline Tahapan & Jumlah & Kategori \\
\hline Tanpa Pengetahuan & 22 & Non-adopter \\
Pengetahuan & 44 & Non-adopter \\
Persuasif & 10 & Non-adopter \\
Keputusan (tidak mengadopsi) & 3 & Non-adopter \\
Keputusan (mengadopsi) & 15 & Adopter \\
Implementasi & 12 & Adopter \\
Konfirmasi & 16 & Adopter \\
\hline
\end{tabular}

Sumber: Data Primer Diolah, 2021 
tanpa pengetahuan, pengetahuan, persuasif, keputusan (tidak mengadopsi), dan kategori adopter yang mencakup keputusan (mengadopsi), implementasi, konfirmasi, dilakukan merujuk pada penelitian yang dilakukan oleh Sirajuddin (2019) mengenai adopsi inovasi dalam pertanian.

Tabel 3, bahwa mayoritas responden (79 responden) tidak mengadopsi jajar legowo dan hanya 43 responden yang telah mengadopsi. Hal ini menunjukkan bahwa hanya $35 \%$ petani responden yang telah mengadopsi jajar legowo. Temuan ini serupa dengan penelitian yang dilakukan oleh Effendy dan Yunika (2020), di Kecamatan Cikoneng, Ciamis, yang menunjukkan bahwa hanya $34 \%$ petani yang telah menggunakan metode tanam jajar legowo. Dibandingkan metode tanam konvensional seperti sistem tegel, jajar legowo belum begitu terdiseminasi di kalangan petani. Masalah serupa juga terlihat dalam penelitian yang dilakukan oleh Farid dkk. (2018), yang menunjukkan bahwa sebagian besar petani di Desa Sukosari, Malang, tidak menerapkan pola tanam jajar legowo.Lebih jauh, data pada Tabel 3 memperlihatkan bahwa masih terdapat sejumlah petani yang belum pernah sama sekali mendengar tentang metode tanam jajar legowo. Hal tersebut mengindikasikan bahwa sosialisasi mengenai jajar legowo masih belum maksimal dilakukan dalam penyuluhan pertanian, utamanya melalui demonstrasi oleh penyuluh lapangan.

\section{Persepsi Petani terhadap Atribut Inovasi Jajar Legowo}

Persepsi petani terhadap metode tanam jajar legowo diukur melalui pertanyaan yang mengindikasikan pandangan responden terhadap atribut inovasi yaitu keuntungan relatif, kompatibilitas, kompleksitas, trialabilitas, dan observabilitas. Persepsi ditunjukkan oleh responden yang pernah melihat langsung dan menggunakan jajar legowo yaitu responden yang berada pada tahap persuasif, keputusan, implementasi, dan konfirmasi. Oleh karena itu, jumlah responden yang merespon pertanyaan mengenai persepsi ini adalah sebanyak 56 responden.

Tabel 4, bahwa responden pada umumnya memandang positif untuk seluruh atribut inovasi jajar legowo. Di antara seluruh atribut yang dinilai, atribut observasibilitas mendapatkan akumulasi nilai tertinggi untuk gabungan setuju dan sangat setuju dalam persepsi petani, dimana pada atribut observasi terdapat total 49 responden $(87,5 \%)$ yang menyatakan setuju dan sangat setuju bahwa penggunaan jajar legowo dapat dilihat dan diobservasi penggunaannya. Aspek observabilitas, sebagaimana didefinisikan oleh Rogers (2003), adalah sejauh mana sebuah inovasi dapat terlihat penggunaan dan hasilnya oleh pengguna. Hal ini menunjukkan bahwa inovasi jajar legowo cukup dapat terobservasi oleh petani di Desa Balahu. Sebagai bagian dari teknologi yang ditawarkan dalam Pengelolaan Tanaman Terpadu (PTT), jajar legowo memang cukup sering diperlihatkan baik oleh penyuluh maupun petani melalui demonstrasi lapangan. Sejalan dengan penelitian Maryani dkk. (2014), berpendapat bahwa sebuah inovasi cenderung mudah diadopsi oleh petani apabila hasilnya dapat dilihat dan dirasakan langsung oleh petani.

Penilaian responden terhadap atribut trialabilitas terhitung paling rendah sebab diantara atribut-atribut lainnya, terdapat 17 responden (30\%) yang menyatakan tidak setuju dan berpandangan netral bahwa metode tanam jajar legowo dapat diujicobakan (trialable) pada lahan yang kecil. Malahayatin dan Cahyono (2017) mengungkapkan bahwa cara tanam jajar legowo, menurut petani di Kecamatan Widang, Kabupaten Tuban sulit untuk diujicoba di atas lahan sempit sebab jarak lorong yang lebih lebar dibanding metode tegel. Meski begitu, penelitian ini menunjukkan bahwa petani memiliki persepsi yang cukup baik mengenai trialabilitas metode tanam jajar legowo. 
Tabel 4

Persepsi Petani terhadap Atribut Inovasi Jajar Legowo

\begin{tabular}{lccccc}
\hline Atribut Inovasi & \multicolumn{5}{c}{ Persepsi Responden } \\
\cline { 2 - 6 } & STS & TS & N & S & SS \\
\hline Keuntungan relatif & 0 & 3 & 13 & 29 & 11 \\
Kompatibilitas & 0 & 5 & 9 & 26 & 16 \\
Kompleksitas & 0 & 5 & 12 & 22 & 17 \\
Trialabilitas & 0 & 5 & 13 & 33 & 5 \\
Observabilitas & 0 & 4 & 3 & 40 & 9 \\
\hline
\end{tabular}

Sumber: Data Primer Diolah, 2021

Tabel 5

Korelasi antara Karakteristik Demografi terhadap Adopsi Jajar Legowo

\begin{tabular}{lccc}
\hline \multicolumn{1}{c}{ Item } & Koefisien Korelasi & Signifikansi & Keterangan \\
\hline Usia & -.005 & .959 & ts \\
Luas Lahan & .235 & .009 & $s^{* *}$ \\
Tanggungan keluarga & -.044 & .628 & ts \\
\hline
\end{tabular}

Ket: ${ }^{* *}$ signifikan pada alpha .01

Sumber: Data Primer Diolah, 2021

Hubungan antara Karakteristik Demografi dengan Tingkat Adopsi Jajar Legowo

Leeuwis dan Van den Ban (2004), berpandangan bahwa adopsi terhadap inovasi salah satunya dapat dipengaruhi oleh karakter demografi individu yang beragam. Penelitian ini mengukur hubungan antara karakteristik demografi responden terhadap tingkat adopsi jajar legowo, dimana karakteristik yang dimaksud adalah usia responden, luas lahan, dan jumlah tanggungan keluarga. Adapun tingkat adopsi jajar legowo diukur melalui variabel tahapan keputusan inovasi jajar legowo. Hubungan korelasi diukur dengan menggunakan Spearman's Rank, dengan hasil sebagaimana terlihat pada Tabel 5.

Tabel 5, menunjukkan bahwa di antara ketiga karakteristik demografi responden, luas lahan memiliki korelasi yang signifikan dengan adopsi jajar legowo. Hal ini ditunjukkan oleh hasil uji korelasi Spearman's Rank, dengan nilai koefisien korelasi yaitu .235, signifikan pada nilai alpha .01. Hubungan korelasi bersifat positif, yang berarti bahwa semakin luas kepemilikan lahan petani, semakin tinggi pula posisi mereka dalam tahapan keputusan inovasi jajar legowo. Hal ini mengindikasikan bahwa kepemilikan lahan yang luas akan semakin mendukung adopsi inovasi jajar legowo. Adapun kekuatan korelasi pada variabel ini adalah .235 yang menunjukkan bahwa kekuatan korelasi yang terdapat pada kedua variabel ini bersifat medium atau menengah (Cohen, 2013). Sementara itu, Hutapea dkk. (2013), menunjukan dalam penelitiannya bahwa bahwa luas lahan berpengaruh positif terhadap kecepatan adopsi inovasi pertanian. Umumnya, petani yang memiliki lahan yang sempit memiliki pertimbangan resiko yang lebih tinggi terhadap kegagalan penerapan inovasi baru yang diterapkan sehingga lebih enggan untuk mengadopsi inovasi baru.

\section{Hubungan antara Persepsi Petani} dengan Tingkat Adopsi Jajar Legowo

Hubungan antara persepsi petani dengan tingkat adopsi jajar legowo menggunakan lima atribut inovasi yaitu keuntungan relatif, kompatibilitas, kompleksitas, trialabilitas, dan observabilitas. Korelasi terhadap tahapan keputusan inovasi diukur dengan 
menggunakan Spearman's Rank. Tabel 6 menunjukkan korelasi antara persepsi responden mengenai atribut inovasi dengan adopsi jajar legowo.

Hasil uji korelasi Spearman's Rank menunjukkan bahwa terdapat korelasi yang sangat kuat $(p$-value $=.01)$ antara atribut kompatibilitas dan kompleksitas dengan adopsi jajar legowo. Hal tersebut terlihat dari nilai korelasi pada kompatibilitas dan kompleksitas yakni .427 dan .379 berturutturut,dengan kekuatan korelasi yang kuat untuk atribut kompatibilitas dan menengah untuk atribut kompleksitas. Untuk atribut observabilitas, korelasi cukup signifikan pada alpha .05 dan kekuatan korelasi medium. Arah korelasi yang positif pada ketiga atribut menunjukkan bahwa semakin meningkat persepsi petani terhadap ketiga atribut tersebut, posisi petani dalam tahapan adopsi juga semakin tinggi. Hasil tersebut mengindikasikan bahwa sangat penting untuk mempertimbangkan persepsi petani terhadap aspek kecocokan (kompatibilitas), kemudahan (kompleksitas), dan keterbukaan terhadap melihta langsung penggunaan jajar legowo (observabilitas).

Atribut kompatibilitas merupakan variabel yang memiliki korelasi yang paling kuat. Hal ini menunjukkan bahwa persepsi atas kecocokan inovasi jajar legowo berhubungan erat dengan adopsi, dimana ketika petani memandang positif bahwa inovasi jajar legowo ini cocok untuk dilakukan di lahan mereka, maka kecenderungan untuk menerapkan jajar legowo juga semakin tinggi. Hasil ini sejalan dengan penelitian yang dilakukan oleh
Rosadillah dkk. (2017), yang menunjukkan bahwa terdapat korelasi yang sangat kuat antara kompatibilitas jajar legowo dengan adopsi terhadap metode tersebut, dimana petani beranggapan bahwa penggunaan jajar legowo membutuhkan peralatan yang kurang lebih serupa dengan metode tanam tegel yang umum dilakukan oleh petani sehingga tidak perlu membeli peralatan baru. Sharifzadeh dkk. (2017), yang meneliti tentang adopsi pengendalian biologis oleh petani di Iran, menemukan bahwa aspek kompatibilitas menjadi determinan adopsi penggunaan teknik pengendalian biologis. Mannan dkk. (2017), berpendapat bahwa inovasi yang kompatibel dengan inovasi sebelumnya, atau inovasi eksisting yang dilakukan oleh petani akan lebih besar kemungkinan untuk diadopsi. Dalam hal penelitian ini, ketika inovasi jajar legowo dipandang cocok dengan inovasi yang sementara dilakukan oleh petani (sistem tegel), maka akan lebih besar potensi untuk diadopsi.

Persepsi petani terhadap atribut kompleksitas jajar legowo berkorelasi sangat kuat dengan tingkat adopsi sehingga dapat dikatakan bahwa ketika petani menganggap jajar legowo tidak rumit untuk dilakukan, maka kecenderungan untuk mengadopsi juga tinggi. Maryani dkk. (2014), mengemukakan bahwa terdapat petani non adopter jajar legowo yang menganggap bahwa penggunaan metode tanam jajar legowo lebih rumit dibandingkan cara yang mereka lakukan saat ini. Petani yang menganggap rumit sebuah inovasi akan lebih membutuhkan pendampngan dari penyuluh sehingga dapat mereduksi

Tabel 6

Korelasi antara Persepsi Petani terhadap Adopsi Jajar Legowo

\begin{tabular}{lccc}
\hline Atribut Inovasi & Koefisien Korelasi & Signifikansi & Keterangan \\
\hline Keuntungan relatif & .164 & .228 & ts \\
Kompatibilitas & .427 & .001 & $\mathrm{~s}^{* *}$ \\
Kompleksitas & .379 & .004 & $\mathrm{~s}^{* *}$ \\
Trialabilitas & .261 & .052 & ts \\
Observabilitas & .270 & .050 & $\mathrm{~s}^{*}$ \\
\hline
\end{tabular}

Ket: ${ }^{* *}$ signifikan pada alpha $.01,{ }^{*}$ signifikan pada alpha .05

Sumber: Data Primer Diolah, 2021 
kerumitan sebuah inovasi. Dalam penelitiannya di Malawi mengenai adopsi inovasi pertanian konservatif, Chinseu dkk. (2019), menemukan bahwa petani yang tidak mengadopsi mengalami efek kejut akibat perubahan metode budidaya. Hal ini disebabkan oleh kerumitan yang terdapat pada metode baru yang ditawarkan yang dianggap tidak sesuai dengan kebiasaan yang mereka lakukan dalam aktivitas pertanian keseharian mereka. Oleh karena itu, untuk menurunkan persepsi negatif mengenai kompleksitas jajar legowo, diperlukan kerjasama pihak-pihak terkait utamanya dalam mendemonstrasikan dan memberikan contoh penggunaan jajar legowo kepada petani. Hal ini sesuai dengan pendapat Eastwood dkk. (2017), yang beranggapan bahwa kolaborasi sangat penting untuk dilakukan, utamanya ketika petani mengalami kesulitan dalam menerapkan inovasi. Kerumitan tersebut dapat ditangani melalui demonstrasi lapangan, kerjasama dalam desain pelatihan, dan pemahaman mendalam akan kebutuhan petani terhadap teknologi yang ditawarkan.

Persepsi petani mengenai atribut observabilitas mengindikasikan kesetujuan petani bahwa metode tanam jajar legowo mudah diihat bukti penggunaan maupun hasilnya, dimana dalam penelitian ini ditemukan bahwa terdapat korelasi yang cukup kuat antara persepsi observabilitas dengan posisi petani dalam tahapan adopsi. Hal tersebut menunjukkan bahwa petani yang berpandangan positif mengenai observabilitas jajar legowo akan cenderung mengadopsi metode jajar legowo tersebut. Hasil ini selaras dengan pandangan Maryani dkk (2014), bahwa umumnya petani mesti merasakan dan melihat hasil dari suatu inovasi agar dapat mempelajari dan mengadopsinya. Sejalan dengan penelitian McCann dkk. (2015), mengungkapkan dalam penelitiannya bahwa inovasi pertanian dalam hal penerapan pertanian ramah lingkungan lebih mudah diadopsi oleh petani apabila proses maupun efeknya dapat terobservasi (visible) oleh petani. Umumnya petani di pedesaan memiliki tingkat pendidikan yang rendah sehingga untuk meyakinkan petani diperlukan usaha dengan cara memperlihatkan cara dan hasil inovasi jajar legowo agar petani percaya bahwa dengan menggunakan jajar legowo, hasil panen dapat ditingkatkan.

Secara umum, dapat dikatakan bahwa persepsi petani mengenai atribut inovasi jajar legowo berkorelasi terhadap kecenderungan mereka untuk mengadopsi jajar legowo yang ditunjukkan melalui posisi mereka dalam tahapan keputusan adopsi jajar legowo. Dengan begitu, persepsi petani yang positif mengenai atributatribut inovasi jajar legowo berhubungan dengan peluang untuk mendiseminasikan inovasi jajar legowo di tingkat petani. Dengan memahami hubungan tersebut dapat berimplikasi pada desain strategi komunikasi penyuluhan pertanian dalam mendorong akselerasi adopsi inovasi jajar legowo.

\section{SIMPULAN}

Tingkat adopsi jajar legowo oleh petani padi dan jagung berdasarkan tahapan keputusan inovasi pengadopsi masih tergolong rendah, dimana hanya 35\% petani yang berada pada tahapan telah mengadopsi. Petani memiliki persepsi yang cukup baik mengenai atribut inovasi metode tanam jajar legowo, utamanya pada atribut observabilitas dan kompatibilitas jajar legowo. Penelitian ini membuktikan bahwa luas lahan berkorelasi sangat kuat dengan posisi petani pada tahapan keputusan inovasi jajar legowo, sehingga semakin luas lahan petani, kecenderungan untuk mengadopsi jajar legowo juga makin kuat. Persepsi petani terhadap aspek kompatibilitas, kompleksitas, dan observabilitas jajar legowo berkorelasi sangat kuat dengan posisi petani pada tahapan keputusan inovasi jajar legowo. Hal tersebut membuktikan bahwa semakin baik persepsi petani mengenai kecocokan metode tanam jajar legowo, kemudahan penerapannya, serta visibilitas penggunaan dan hasilnya, semakin besar pula potensi bahwa metode tanam jajar 
legowo akan diadopsi petani. Implikasi penelitian ini adalah pada peningkatan desain strategi komunikasi dalam penyuluhan pertanian untuk mendorong percepatan adopsi teknologi dalam pertanian, utamanya pertanian tanaman pangan padi dan jagung. Dalam penelitian ini ditemukan bahwa penyuluhan pertanian perlu mendesain strategi komunikasi yang dapat meningkatkan persepsi positif petani terhadap jajar legowo, utamanya dalam hal kompatibilitas, kompleksitas, dan observabilitas.

\section{DAFTAR PUSTAKA}

Aisyah, S., \& Dinar. (2016). Peranan penyuluhan pertanian terhadap penerapan sistem tanamjajarlegowo. (Suatu kasus pada kelompok tani di Kecamatan Cigasong Kabupaten Majalengka). Agrivet: Jurnal IImuIImu Pertanian Dan Peternakan, 4(2), 181-195.

Ary, D., Jacobs, L. C., Irvine, C. K. S., \& Walker, D. (2018). Introduction to research in education (10th Editi). Boston, MA: Cengage Learning.

Badan Pusat Statistik. (2020). Kecamatan Tibawa dalam Angka 2020.

Chinseu, E., Dougill, A., \& Stringer, L. (2019). Why do smallholder farmers dis-adopt conservation agriculture? Insights from Malawi. Land Degradation and Development, 30(5), 533-543. https://doi. org/10.1002/ldr.3190

Cohen, J. (2013). Statistical Power Analysis for the Behavioral Sciences. In Statistical Power Analysis for the Behavioral Sciences. https://doi. org/10.4324/9780203771587

Donggulo, C. V., Lapanjang, I. M., \& Made, U. (2017). Pertumbuhan dan hasil tanaman padi (Oryza sativa L) pada berbagai pola jajar legowo dan jarak tanam. Jurnal Agroland, 24(1), 27-
35.

Eastwood, C., Klerkx, L., \& Nettle, R. (2017). Dynamics and distribution of public and private research and extension roles for technological innovation and diffusion: Case studies of the implementation and adaptation of precision farming technologies. Journal of Rural Studies, 49, 1-12. https://doi. org/10.1016/j.jrurstud.2016.11.008

Effendy, L., \& Yunika, C. (2020). Model peningkatan minat petani pada penerapan teknologi tanam jajar legowo padi sawah di Kecamatan Cikoneng Ciamis. Agritexts : Journal of Agricultural Extension, 44(2), 7583.

Fachrista, I. A., \& Sarwendah, M. (2014). Persepsi dan tingkat adopsi petani terhadap inovasi teknologi pengelolaan tanaman terpadu padi sawah. Jurnal Agriekonomika, 3(1), $1-10$.

Farid, A., Romadi, U., \& Witono, D. (2018). Faktor-faktor yang mempengaruhi adopsi petani dalam penerapan sistem tanam jajar legowo di Desa Sukosari Kecamatan Kasembon Kabupaten Malang Provinsi Jawa Timur. Jurnal Penyuluhan, 14(1), 27-32. https://doi.org/10.25015/ penyuluhan.v14i1.19226

Gunawan, G., Hubeis, A. V. S., Fatchiya, A., \& Susanto, D. (2019). Dukungan penyuluhan dan lingkungan ekternal terhadap adopsi inovasi dan keberlanjutan usaha pertanian padi organik. Jurnal Agriekonomika, 8(1), 70. https://doi.org/10.21107/ agriekonomika.v8i1.4951

Hutapea, Y., Suparwoto, \& Efendy, J. (2013). Kecepatan adopsi varietas unggul dan kelayakan usahatani kedelai di Sumatera Selatan. Jurnal Agriekonomika, 2(2), 123-138. 
Kuntariningsih, A., \& Mariyono, J. (2014). Adopsi teknologi pertanian untuk pembangunan pedesaan: Sebuah kajian sosiologis. Jurnal Agriekonomika, 3(2), 180-191.

Leeuwis, C., \& Van den Ban, A. (2004). Communication for Rural Innovation : Rethinking Agricultural Extension (3rd ed.). Oxford:UK: Blackwell Science.

Malahayatin, D. M., \& Cahyono, E. D. (2017). Faktor kesesuaian dengan kebutuhan petani dalam keputusan adopsi inovasi pola tanam jajar legowo (Studi kasus petani padi di Kecamatan Widang, Kabupaten Tuban). JEPA-Jurnal Ekonomi Pertanian Dan Agribisnis, 1(1), 5661.

Mannan, S., Nordin, S. M., Rafik-Galea, S., \& Ahmad Rizal, A. R. (2017). The ironies of new innovation and the sunset industry: Diffusion and adoption. Journal of Rural Studies, 55, 316-322. https://doi. org/10.1016/j.jrurstud.2017.07.015

Maryani, N., Suparta, N., \& Setiawan, I. (2014). Adopsi inovasi PTT pada Sekolah Lapang Pengelolaan Tanaman Terpadu (SL-PTT) padi di Kecamatan Sukawati, Kabupaten Gianyar. Jurnal Manajemen Agribisnis, 2(2), 84-102.

McCann, L., Gedikoglu, H., Broz, B., Lory, J., \& Massey, R. (2015). Effects of observability and complexity on farmers' adoption of environmental practices. Journal of Environmental Planning and Management, 58(8), 1346-1362. https://doi.org/10.1080/ 09640568.2014.924911

Rogers, E. M. (2003). Diffusion of Innovations (5th ed.). New York: Free Press.
Rosadillah, R., Fatchiya, A., \& Susanto, D. (2017). Penerapan pengelolaan tanaman terpadu padi sawah di Kecamatan Toili, Kabupaten Banggai, Sulawesi Tengah. Jurnal Penyuluhan, 13(2), 143. https:// doi.org/10.25015/penyuluhan. v13i2.15052

Sharifzadeh, M. S., Damalas, C. A., Abdollahzadeh, G., \& Ahmadi-Gorgi, H. (2017). Predicting adoption of biological control among Iranian rice farmers: An application of the extended technology acceptance model (TAM2). Crop Protection, 96, 88-96. $\quad$ https://doi.org/10.1016/j. cropro.2017.01.014

Sirajuddin, Z. (2019a). Pemanfaatan teknologi informasi dan komunikasi (TIK) untuk meningkatkan laju adopsi teknologi pertanian. Telaah literatur. Temu Aplikasi Teknologi Dan Seminar Nasional: Akselerasi Inovasi Pertanian Era Industri 4.0 Mendukung Kawasan Pertanian Sejahtera (SAPIRA).

Sirajuddin, Z. (2019b). The adoption of Cyber-Extension in Indonesia: Impact of extension agents' perception of Cyber Extension's innovation attributes and Information and Communication Technology (ICT) proficiency (lowa State University). Retrieved from https://lib.dr.iastate. edu/etd/17319

Taylor, C., \& Miller, G. (2016). Examining eXtension: Diffusion, disruption, and adoption among lowa State University Extension and Outreach professionals. Journal of Extension, 54(5). 